\title{
Functional performance levels of strength and power needed for independence in $\mathbf{8 0}$-year-old individuals
}

\author{
Mieko Shimada ${ }^{1}$, Yoshiaki Nomura ${ }^{2}$, Yasuo Kimura ${ }^{3}$, Naoki Nakagawa ${ }^{4}$, Hiroshi Nagayama ${ }^{5}$, \\ Mitsumasa Tazawa ${ }^{6}$, Tamotsu Sato ${ }^{7}$, Daisuke Inaba ${ }^{8}$, Masami Yonemitsu ${ }^{8}$, Yutaka Yoshitake ${ }^{9}$ \\ ${ }^{1}$ Faculty of Health Care Sciences, Chiba Prefectural University of Health Sciences, Chiba, Japan \\ ${ }^{2}$ School of Dental Medicine, Tsurumi University, Yokohama-shi, Japan \\ ${ }^{3}$ Faculty of culture and education, Saga University, Saga, Japan \\ ${ }^{4}$ School of Information-oriented Management, Sports Management Research Center, SANNO University, Kanagawa, Japan \\ ${ }^{5}$ Fukuoka University, Fukuoka, Japan \\ ${ }^{6}$ Office Tazawa Company, Iwate, Japan \\ ${ }^{7}$ Iwate Dental Association, Iwate, Japan \\ ${ }^{8}$ Department of Oral Medicine, Division of Preventive Dentistry Iwate Medical University, Iwate, Japan \\ ${ }^{9}$ Department for Interdisciplinary Studies of Lifelong Sport and Physical Activity, National Institute of Fitness \& Sports in Kanoya, \\ Kagoshima, Japan \\ Email:mieko.shimada@cpuhs.ac.jp
}

Received 2 May 2012; revised 5 June 2012; accepted 18 June 2012

\begin{abstract}
Background: The ability to climb stairs (ascending and descending stair without using a handrail) and rise from a chair (rising from chairs without using an elbow rest) are among the most important measures of physical function for ADL evaluation for the independent living, and assessed by the questioners on many epidemiological studies in elderly. But little is known about the relationship between the self-reported performance level of the tasks and lower leg strength and power in very elderly people. The purpose of this study was to ascertain the relationship between the self-reported performance level of two tasks and the lower leg function in communitydwelling 80-year-old population. Methods: Out of 994 persons who were 80 years old living in Morioka City, Iwate Prefecture, Japan, 607 individuals (236 men and 371 women) underwent a physical fitness test that included measurements of leg extensor power and knee extensor strength. The ability to climb up stair and to rise from a chair was assessed by selfreported questionnaire which was ranked in three levels. The area under the receiver-operating characteristic (ROC) curve (AUC) was used to evaluate the measurements. Results: The cut-off points for the leg extensor power of subjects who could completely perform the stair-climbing and chair-rising functions were determined to be approximately 8.6 watt $/ \mathrm{kg}$ body mass for men and 5.6 watt $/ \mathrm{kg}$ body mass for women. In addition, the cut-off points for the knee extensor strength of subjects who could completely
\end{abstract}

perform the stair-climbing and chair-rising functions were determined to be approximately $0.97 \mathrm{~kg} / \mathrm{kg}$ body mass for men and $0.84 \mathrm{~kg} / \mathrm{kg}$ body mass for women. Conclusions: From a practical viewpoint, the present study suggested that the cut-off points of leg extensor power and knee extensor strength can be used as targets in simple self-reported questionnaires to help in screening for mobility in 80-year-old population

Keywords: Elderly; Leg Extensor Power; Knee Extensor Strength; ADL Independence; Cut-Off Point

\section{INTRODUCTION}

The number and proportion of people aged 65 years or older in the population are increasing rapidly in both Japan and other industrialized countries. In these countries, the prevention of disabilities of the elderly is an important political issue since many disabled elderly may require future hospitalization and long-term care.

Recent research has shown that older persons who perform poorly on standardized tests of lower extremity strength are at a higher risk of developing disabilities $[1,2]$. Although the causes of impaired mobility are multiple, lower leg muscle function obviously plays a major role in mobility. Walking, stair-climbing and chair-rising are common daily activities and an essential function for physical independence, and these functions are identified persons having problem with instrumental and daily activities of daily living in both Japan and other industrialized countries. Of these daily physical activities, the ability to ascend and descend stairs successfully seems to 
require greater strength in the lower extremities than many other activities of daily living (ADL) [3]. Stair negotiation correlates well with other measures of functional disability in the elderly and is useful in assessing a wide range of individual abilities [4], and capture a wide spectrum of medical, clinical, and functional status in older adults [5].

Therefore, the stair and chair negotiation are an excellent mobility performance measure [6] and the performance of the tasks is also a marker of health status superior to any other biochemical measure and one of the main determinants of quality of life in old age [7].

The statistically significant association between leg muscle strength and self-reported stair-climbing performance [9,10]. Ploutz-Snyder et al. [11] suggested a critical knee extensor strength which is required to accomplish basic functional tasks (chair-rising, gait speed, and stair ascent and descent). Other studies reported the existence of a threshold or an optimal cut-off point in lower extremity performance for physical independence in the elderly who live independently [12-18].

However, these studies have certain limitations because they were conducted in relatively small groups of elderly subjects, which limited the ability to identify the threshold and generalization of the obtained results. In most of these studies, the threshold level did not account for sex, in spite of gender differences in self-reported performance and performance-based physical fitness $[16,19]$. Although an association between self-reported stair-climbing and chair-rising, and lower leg strength and power seems established in the elderly, that association has been examined primarily in individuals under the age of 80 years. Because of increases in longevity in Japan, however, the number of people older than 80 is growing, thus necessitating investigation of these very elderly. Few studies have dealt with elderly subjects above the age of 80 . However, little is known about this relationship of the performance of self-reported stair and chair negotiation with the lower leg strength and power in a very elderly population. In the present study, this association was evaluated in an 80-year-old population.

\section{SUBJECTS AND METHOD}

\subsection{Subjects}

The survey was conducted in 80-year-old subjects (born in 1918) residing in eight areas under the jurisdiction of Morioka Public Health Center, Iwate Prefecture, Japan. It was conducted from September to November 1997 at eight locations in town community centers or public health centers. The survey sample was drawn from the official resident file. At the time of the survey in 1997, 994 people aged 80 lived in Morioka. All the subjects were invited for a medical checkup that involved measurement of their physical fitness levels and completion of questionnaires. Subjects living in nursing homes were excluded. Out of 994 persons, 607 individuals (61.1\%, 236 men and 371 women) underwent a physical fitness test including the leg extensor power and knee extensor strength.

Prior to the start of the present study, the consent of the ethics committee of the Iwate Medical University School of Dentistry was obtained, and subjects were volunteers who had given informed, written approval.

\subsection{Survey Instruments}

One week prior to the check-ups, the questionnaire was sent by mail. The questionnaire was collected before the medical check-ups. The question on ability of stairclimbing was worded as "How is your ability to walk up and down stairs without the use of the handrail?” and the question on ability of chair-rising was worded as "How is your ability to sit down and rise from a seated position without the use of a chair's arm?” On two tasks, the subjects were asked to choose one of three options; good, fair or unable.

\subsection{Measurement of Physical Fitness}

Physical fitness measurements were carried out only for subjects who were sufficiently fit based on electrocardiograms, blood pressure, or a physician's interviews.

1) Isometric knee extensor strength: As a measure of the muscular strength in the lower limbs, the maximum isometric bilateral muscle strength of the quadriceps was determined by using a portable chair incorporating a strain gauge connected to a load cell (Remodeling of Digital muscular strength meter, Yagami Inc., Nagoya, Japan). The load cell was connected by a wire to the belt, which could be adjusted such that the subject could sit comfortably with the leg hanging vertically and the knee bent at $90^{\circ}$. The subjects were given strong verbal encouragement and visual feedback from the digital display. The test was performed on the right and left legs, respectively. The best score from two trials was recorded for each leg.

2) Leg extensor power: As a measure of the muscular power in the lower limbs, the maximum bilateral leg extensor power was determined using an isokinetic dynamometer (Anaeropress 3500, Combi Co., Tokyo, Japan). The apparatus is designed for measuring the explosive power of the leg extension and has been reported to be reliable, valid [20], and feasible [21] in subjects of both sexes ranging in age from 16 to 84 years. The subjects sit on the seat and press their feet on the plate as hard as they can in a horizontal direction until the leg is fully extended. The body mass of each subject is used for 
resistance. The subjects were given strong verbal encouragement and visual feedback from the instrument display to produce the maximal voluntary force. Each subject performed five trials at 10 -s intervals, and the best score from the five trials was recorded.

\subsection{Statistical Analyses}

To study the relationship between the level of physical fitness and functional independence in the ADL, subjects were divided into two groups based on their responses. Group 1 (Able) consisted of subjects whose response was "good" or "fair", whereas group 2 (Unable) comprised those whose answer was "unable to do".

All data are presented as means \pm SD. Unpaired $t$-test (two-tailed) and Chi-square test were used to evaluate differences within each gender. The receiver-operating characteristic (ROC) curve was used to determine the diagnostic cut-off points and to compare the diagnostic accuracy between power and strength. The sensitivity, specificity, and positive and negative predictive values were calculated, and the cut-off point was determined as the minimum discrepancy between the sensitivity and specificity. The difference between the areas under curves was tested by the independent $\mathrm{Z}$ test [22]. Statistical significance was accepted when $\mathrm{p}<0.05$. Most of the data were analyzed using SPSS11.0 (SPSS Inc., Chicago, IL).

\section{RESULTS}

Table 1 shows the details of the subjects. The sample consisted of men $(n=236)$ and women $(n=371)$ residing in the same prefecture. Of these subjects, $88.1 \%$ of the men and $80.3 \%$ of the women were tested for the leg extensor power, while $91.5 \%$ of the men and $86.8 \%$ of the women were assessed for knee extensor strength. With regard to the physical characteristics and physical fitness levels, significantly higher values were observed for the men than for the women. Pain in the legs was reported by $45 \%$ of the men and $55 \%$ of the women.

The physical fitness variables were compared between individuals who claimed to be able to perform the two ADLs (stair-climbing and chair-rising) without or with difficulty (Table 2). Separate comparisons were made for the stair-climbing and chair-rising abilities. In men and women, the leg extensor power and knee extensor strength were significantly higher in the Able group than in the Unable group for both the stair-climbing and chair-rising tasks ( $\mathrm{p}<0.0001)$.

The cut-off point and histogram for the two groups are shown in Figure 1 (stair-climbing) and Figure 2 (chairrising). The cut-off points for leg extensor power during stair-climbing were calculated to be approximately 8.6 watt $/ \mathrm{kg}$ body mass for men and 5.6 watt $/ \mathrm{kg}$ body mass for women. Similarly, the cut-off values for knee extensor strength during stair-climbing were approximately 0.97 $\mathrm{kg} / \mathrm{kg}$ body mass for men and $0.84 \mathrm{~kg} / \mathrm{kg}$ body mass for women. The cut-off points for leg extensor power during chair-rising were calculated to be approximately 8.4 watt $/ \mathrm{kg}$ body mass for men and 5.4 watt $/ \mathrm{kg}$ body mass for women. The corresponding values for knee extensor strength during chair rising were approximately 0.96 $\mathrm{kg} /$ body mass for men and $0.80 \mathrm{~kg} / \mathrm{kg}$ body mass for women (Table 3).

Table 1. Characteristics of study patients.

\begin{tabular}{|c|c|c|c|c|}
\hline & & Men & Women & \\
\hline Age (yrs) & & $80.3 \pm 0.3(236)$ & $80.3 \pm 0.3(371)$ & \\
\hline \multicolumn{5}{|l|}{ Physical characteristics } \\
\hline Height (cm) & & $156.8 \pm 5.9(228)$ & $142.0 \pm 5.7(358)$ & *** \\
\hline Weight (kg) & & $56.3 \pm 8.9(233)$ & $48.0 \pm 8.3(365)$ & *** \\
\hline Body mass index $\left(\mathrm{kg} / \mathrm{m}^{2}\right)$ & & $22.9 \pm 3.3(228)$ & $23.7 \pm 3.6$ (358) & ** \\
\hline \multicolumn{5}{|l|}{ Physical fitness $^{\#}$} \\
\hline Leg extensor power (watt/kg weight) & & $8.9 \pm 3.0(208)$ & $5.7 \pm 2.1(298)$ & *** \\
\hline No data & & (29) & (73) & \\
\hline Knee extensor strength (kg/kg weight) & & $1.04 \pm 0.34(216)$ & $0.82 \pm 0.31(322)$ & *** \\
\hline No data & & $(20)$ & (49) & \\
\hline \multicolumn{5}{|l|}{ Complaint ${ }^{\# \#}$} \\
\hline \multirow[t]{2}{*}{ A pain in the legs } & Yes & $105(44.5)$ & $204(55.0)$ & \multirow[t]{2}{*}{$\mathrm{HH}$} \\
\hline & No & $130(55.1)$ & $162(43.7)$ & \\
\hline
\end{tabular}

\#Data of age, physical characteristics and physical fitness are expressed as the mean \pm SD (number of subjects). ${ }^{\# \#}$ Data of complaint and ADL questionnaire are expressed as the number of subjects (percentage). ${ }^{* * *} \mathrm{p}<0.0001,{ }^{* *} \mathrm{p}<0.0001$ significant differences in gender (t-test,) ${ }^{\dagger \dagger \dagger} \mathrm{p}<0.0001$ significant differences in gender (chi-square test). 
Table 2. Physical fitness variables.

\begin{tabular}{|c|c|c|c|c|c|c|c|}
\hline & & & & & Able & Unable & $\mathrm{p}$ value \\
\hline \multirow{5}{*}{ Stair-climbing } & \multirow{3}{*}{$\begin{array}{l}\text { Leg extensor power } \\
\text { (watt/kg weight) }\end{array}$} & Men & 9.6 & \pm & $2.7(n=149)$ & $7.1 \pm 2.9(n=58)$ & $* * *$ \\
\hline & & Women & 6.6 & \pm & $2.2(\mathrm{n}=128)$ & $5.1 \pm 1.8(n=166)$ & $* * *$ \\
\hline & & & & & & & \\
\hline & \multirow{2}{*}{$\begin{array}{l}\text { Knee extensor strength } \\
\text { (kg/kg weight) }\end{array}$} & Men & 1.14 & \pm & $0.28(\mathrm{n}=149)$ & $0.82 \pm 0.35(n=66)$ & $* * *$ \\
\hline & & Women & 0.91 & \pm & $0.30(\mathrm{n}=131)$ & $0.76 \pm 0.30(n=186)$ & *** \\
\hline \multirow{5}{*}{ Chair-rising } & \multirow{2}{*}{$\begin{array}{l}\text { Leg extensor power } \\
\text { (watt/kg weight) }\end{array}$} & Men & 9.2 & \pm & $2.9(n=172)$ & $6.9 \pm 2.6(n=35)$ & $* * *$ \\
\hline & & Women & 6.2 & \pm & $2.2(\mathrm{n}=182)$ & $5.0 \pm 1.7(n=116)$ & $* * *$ \\
\hline & \multirow{3}{*}{$\begin{array}{l}\text { Knee extensor strength } \\
\text { (kg/kg weight) }\end{array}$} & & & & & & \\
\hline & & Men & 1.08 & \pm & $0.32(\mathrm{n}=174)$ & $0.77 \pm 0.34(\mathrm{n}=41)$ & $* * *$ \\
\hline & & Women & 0.89 & \pm & $0.3(n=186)$ & $0.73 \pm 0.31(n=136)$ & $* * *$ \\
\hline
\end{tabular}

${ }_{\mathrm{*}}^{* * *} \mathrm{p}<0.0001$ significant differences in groups (t-test).

Table 3. Diagnostic accuracy.

\begin{tabular}{|c|c|c|c|c|c|c|c|}
\hline & & & Optimum cut-off value & Sensitivity & Specificity & $\begin{array}{l}\text { Positive predictive } \\
\text { value }\end{array}$ & $\begin{array}{c}\text { Negative predictive } \\
\text { value }\end{array}$ \\
\hline & & & & & & (\%) & (\%) \\
\hline \multirow{4}{*}{ Stair-climbing } & \multirow{2}{*}{$\begin{array}{l}\text { Leg extensor } \\
\text { power }\end{array}$} & $\begin{array}{c}\text { Men } \\
(\mathrm{n}=207)\end{array}$ & 8.6 (watt/kg weight) & 0.66 & 0.66 & 83.1 & 42.7 \\
\hline & & $\begin{array}{l}\text { Women } \\
(\mathrm{n}=294)\end{array}$ & 5.6 (watt/kg weight) & 0.63 & 0.64 & 57.1 & 68.8 \\
\hline & \multirow{2}{*}{$\begin{array}{l}\text { Knee extensor } \\
\text { strength }\end{array}$} & $\begin{array}{c}\text { Men } \\
(\mathrm{n}=215)\end{array}$ & 0.97 (kg/kg weight) & 0.71 & 0.72 & 84.8 & 52.8 \\
\hline & & $\begin{array}{l}\text { Women } \\
(\mathrm{n}=317)\end{array}$ & 0.84 (kg/kg weight) & 0.64 & 0.62 & 54.5 & 71.2 \\
\hline \multirow{4}{*}{ Chair-rising } & \multirow{2}{*}{$\begin{array}{l}\text { Leg extensor } \\
\text { power }\end{array}$} & $\begin{array}{c}\text { Men } \\
(\mathrm{n}=209)\end{array}$ & 8.4 (watt/kg weight) & 0.63 & 0.63 & 89.3 & 25.9 \\
\hline & & $\begin{array}{l}\text { Women } \\
(\mathrm{n}=298)\end{array}$ & 5.4 (watt/kg weight) & 0.63 & 0.62 & 72.2 & 51.4 \\
\hline & \multirow{2}{*}{$\begin{array}{l}\text { Knee extensor } \\
\text { strength }\end{array}$} & $\begin{array}{c}\text { Men } \\
(\mathrm{n}=215)\end{array}$ & 0.96 (kg/kg weight) & 0.67 & 0.67 & 89.2 & 32.6 \\
\hline & & $\begin{array}{l}\text { Women } \\
(\mathrm{n}=322)\end{array}$ & 0.80 (kg/kg weight) & 0.62 & 0.62 & 68.9 & 54.2 \\
\hline
\end{tabular}

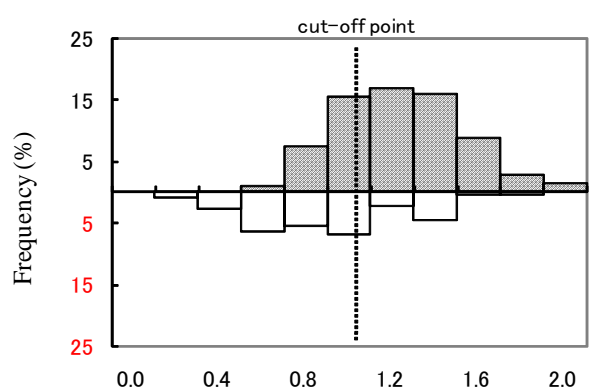

Knee extensor strength (kg/kg weight)

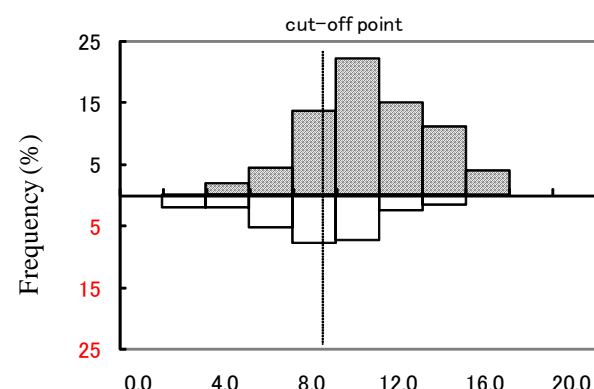

Leg extensor power (watt/kg weight) 

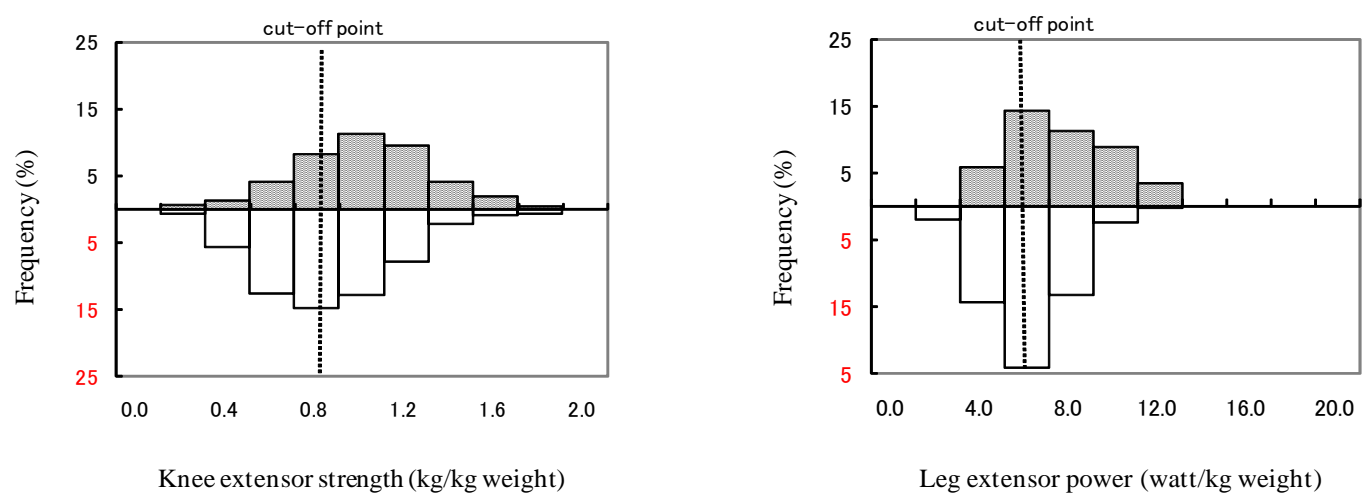

(b)

Figure 1. Cut off point on stair climbing (Knee extensor strength and leg extensor power): (a) Man; (b) Woman.

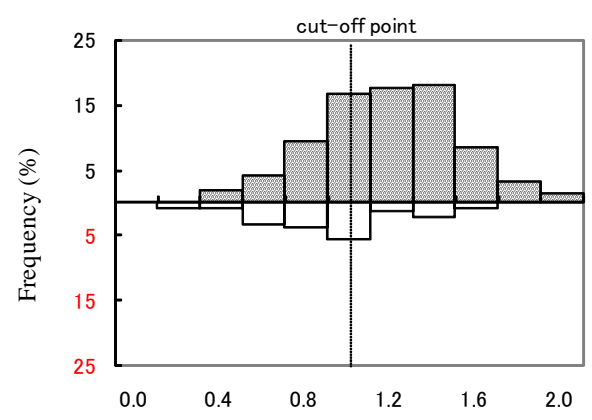

Knee extensor strength (kg/kg weight)

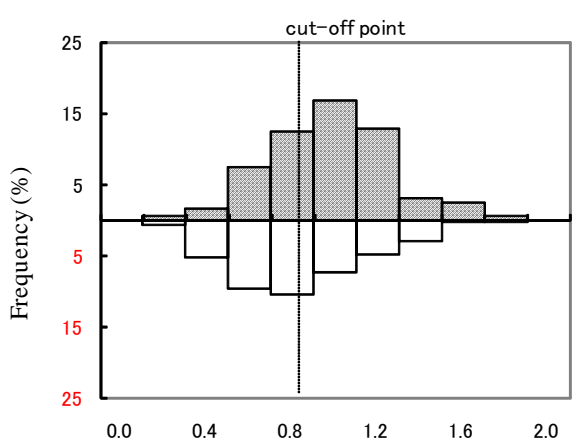

Knee extensor strength (kg/kg weight)

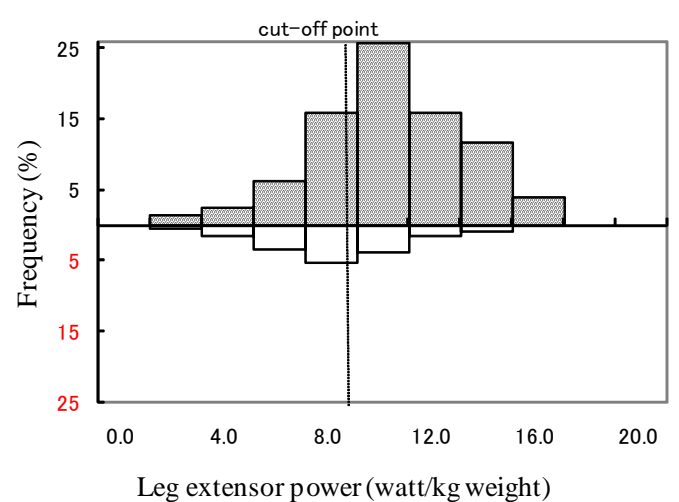

(a)

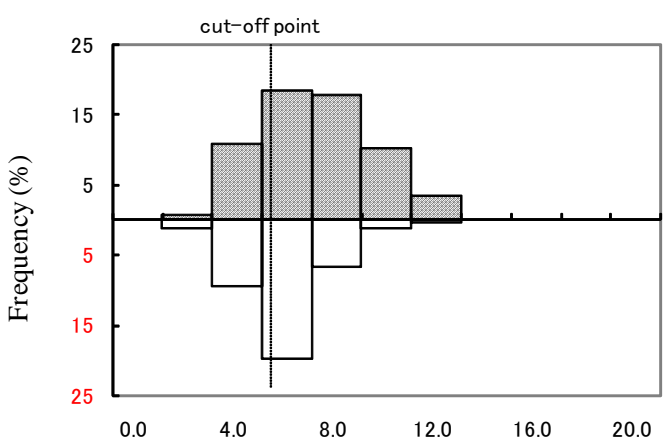

Leg extensor power (watt/kg weight)

(b)

Figure 2. Cut off point on Rising from chairs (Knee extensor strength and leg extensor power): (a) Man; (b) Woman.

Figure 3 (stair-climbing) and Figure 4 (chair-rising) show the resulting ROC curves. For men, the area under the ROC curve (AUC) for stair-climbing was 0.725 (95\% CI: 0.648 - 0.802) for power and 0.756 (95\% CI: 0.680 0.833 ) for strength. For women, the AUC for stairclimbing was 0.698 (95\% CI: 0.638 - 0.759) for power and 0.649 (95\% CI: 0.588 - 0.711) for strength. For men, the AUC for chair-rising was 0.687 (95\% CI: 0.590 0.783 ) for power and 0.702 (95\% CI: 0.610 - 0.794) for strength. For women, the AUC for chair-rising was 0.670 (95\% CI: 0.609 - 0.731) for power nd 0.647 (95\% CI:
$0.585-0.709)$ for strength. All curves were significantly different from the diagonal line that indicates zero predictive ability of the test.

The AUC for strength was greater than that for power in the case of men, but this trend was reversed in the case of women. In both men and women, differences in the areas under the two ROC curves (power and strength) were not statistically significant.

The sensitivity and specificity values for stair-climbing and chair-rising ranged from $63 \%$ to $72 \%$ for men and from $62 \%$ to $64 \%$ for women (Table 3). 


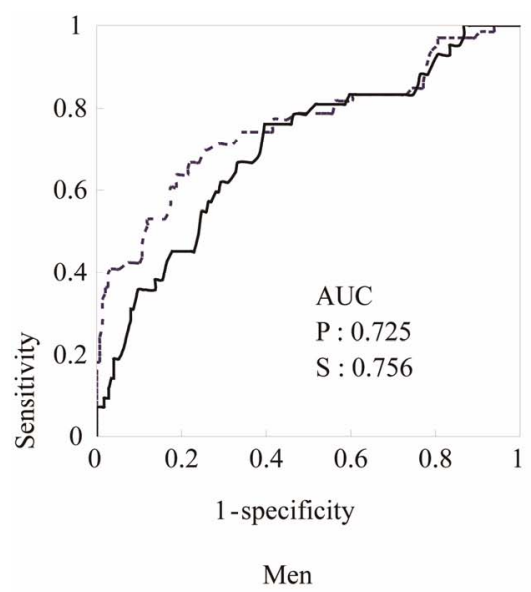

Figure 3. ROC curve on stair-climbing.

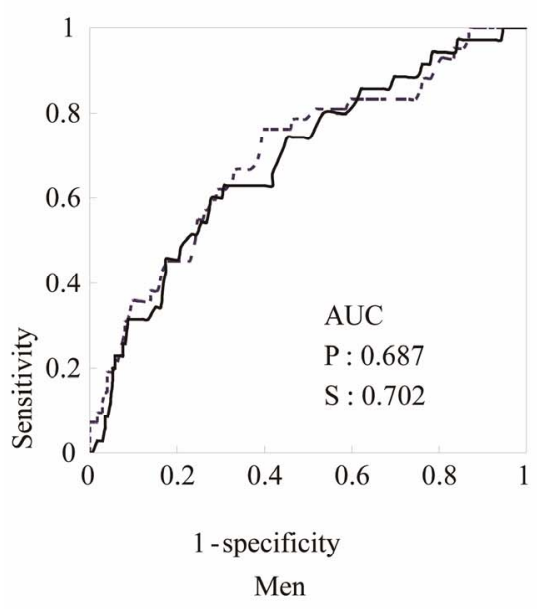

Figure 4. ROC curve on chair-rising.

\section{DISCUSSION}

The purpose of this study was to elucidate usefulness of self-reported ascending and descending stairs and rising chair performance test for screening the mobility, and to examine the levels of lower strength and power necessary to perform the these self-reported tasks on 80-yearold community-dwelling population.

\subsection{Subjects}

One of the strengths of this study is its large sample size ( $n=607$ ) of community-dwelling 80-years old population. In this study, pain in the legs was reported by $44.5 \%$ of the men and $55.0 \%$ of the women. In an older population in Japan, it has been reported that half of the subjects complained of pain in the legs [23]. Among all the persons at the incidence of knee osteoarthritis, $86.7 \%$
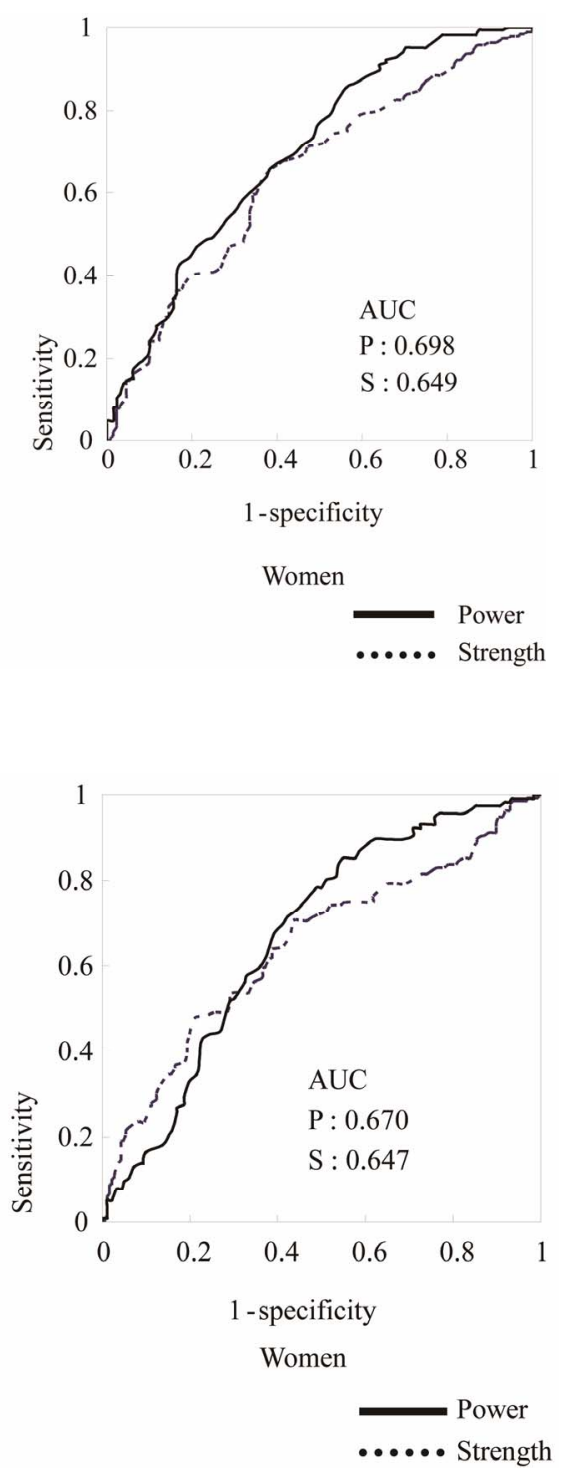

indicated that they always or sometimes needed help on stairs $[24,25]$. Rate of leg pain further increases in very elderly people. These results would suggest that most of very elderly people live with having some troubles in the leg, indicating that leg with pain would be more common among very elderly people. Therefore, the measurements of knee extension strength and leg power were made regardless of the presence of pain in the subject's legs on the present study, so the degree of pain severity was checked at the medical check before the measurements and the peoples with reporting difficulty to perform the measurements was excluded in the present study.

\subsection{Knee Extensor Strength and Leg Extensor Power}

There are many methods for measuring lower extremity 
muscle function. In epidemiological studies, the leg strength in older populations has been generally measured using isometric strength during a shortening contraction [16]. These measures of strength appear to be safe since all the force involved in the measurements is generated by the muscle tested. However, Lauretani et al. [14] reported that lower extremity muscle power was no better than knee extensor torque or handgrip in early identification of poor mobility. Bean et al. [25] reported that muscle power is a more influential proximal determinant of physical performance than impairments in strength and emphasized that muscle power is an important determinant of mobility skills in older adults. Although these studies suggest that muscle power is a more useful measure of lower extremity performance than leg strength, leg power and strength were widely used an index of a lower extremity function. So we examined the cut-off points of leg power and knee extensor strength.

\subsection{Cut-Off Point in This Study}

Previous studies have shown that the optimal cut-off points for the elderly who live independently could be used to predict adverse events in disabled elderly persons $[11,13,15,18]$. The values in the present study were higher than those of previous studies. This is due to the participants living in the community and they need higher levels of muscular performances compared with dependent subjects of previous studies. Although we examined the cut-off points of leg power and knee extensor strength in this study, the lack of lower extremities data (Men about 10\%, Women about 15\%) existed. These results imply that threshold values might be higher than that of previous studies.

Women need to have the same strength as men in order to climb up a stair of a given height [9], however, their climbing capacity without support is lower than that of men [10]. This suggests that in comparison to men, women need to make a greater effort relative to their maximum capacity to perform the stair-climbing and chair-rising task. Therefore, the ability to perform these tasks may be lower in women than in men in the present study.

For both men and women, significantly higher power and strength were observed in individuals who responded that they were able to perform the requested tasks without difficulty, but the magnitude of the difference was small between "Able" and "Unable" group on the strength and power, respectively. This finding is similar to those of previous studies [26]. However, there was a substantial overlap in the distribution of strength and power between the groups (Able and Unable), especially in women. Some women with low strength reported that they could stand from a chair or climb stairs. Conversely, some women with high strength reported that they could not stand from a chair or climb stairs. This is consistent with the findings of Ferrucci et al. in which they showed that there is a substantial overlap in the distribution of strength at a given physical performance level [12].

There are some reasons for the overlap in the distribution of strength and power between the groups based on the self-reported performance of stair and chair negotiation. The self-reported stair and chair negotiation is a measure of mobility which is commonly used assessing the disability in epidemiological studies [27]. Stair negotiation needed an integrative function for strength, endurance, balance, flexibility, and is successfully performed by being smooth coordination of the functions. The plantarflexor and ankle dorsiflexor muscle are important predictors of stair-climbing and chair-rising performance [28]. Morey et al reported that a strong association between directly measured peak oxygen uptake and self-reported physical functioning including stair up and down was reported in older adults [29]. Significant association is also observed between the self-reported activities of daily living scores and peak maximal oxygen uptake and lower leg strength [30]. This would suggest that lower leg strength and cardiorespiratory function are the most important role to perform the stair-ascending and-descending. Furthermore, difficulty in climbing up stairs is associated with poor balance [5]. For example, subjects who foresee the danger of falling when climbing stairs would probably answer that it was difficult, regardless of their actual muscular strength. It is plausible that the AUC values of women are lower than those of men because of the effects of this expected insecurity. The biomechanical performances may influence the overlap in the distributions. Brechter [31] reported that patellofemoral joint stress during stair ambulation for persons with patellofemoral pain was modulated by a reduction in the patellofemoral joint reaction force, which was accomplished through a reduction in the knee extensor moment and a slower cadence. These results would be partly explained the overlap in the distribution of strength and power between the groups based on the self-reported stair negotiation.

On the other hand, the chair negotiation needs very minimal strength to be performed, especially when strength is only limiting factor, and that there is not a clear cut-off-point for “Able” versus "Unable” groups to perform this test in this population. Papa et al. [32] reported that different sit-to-stand motor strategies were identified in the young and elderly subjects. The elder group, as compared with young group, prior to seat-off tended to flex the trunk more, thus bringing the center of mass closer to the base of support, at a higher velocity, thus gaining a higher momentum. These results suggest that older people would use modification strategies to cope with the demands of tasks. These results indicate 
that biomechanical changes might represent a shift away from impairment in chair-rising or stair-climbing. In this study, some women with low strength might have had specific functional strategies in a clinical context.

From a practical viewpoint, the results of the present study suggest that the cut-off point of leg extensor power and knee extensor strength are targets that can be used in simple self-reported questionnaires to help in the prevention of outright disabilities. If such disabilities can be delayed through timely intervention such as physical training, which can help in maintaining and strengthening the body, the number of disability-free years and active life expectancy can be increased.

\section{ACKNOWLEDGEMENTS}

This study was partly supported by a Grant-in-Aid for Research on Health Services (10150201) (Y. Yoshitake) and a Grant-in-Aid for Scientific Research (C) (18500549) (Y. Yoshitake) from the Ministry of Education, Science and Culture of Japan and a Grant-in-Aid for Scientific Research from the National Institute of Fitness and Sports in Kanoya (President's Discretionary Budget, to Y. Yoshitake).

\section{REFERENCES}

[1] Gill, T.M., Williams, C.S. and Tinetti, M.E. (1995) Assessing risk for the onset of functional dependence among older adults: The role of physical performance. Journal of the American Geriatrics Society, 43, 603-609.

[2] Guralnik, J.M., Ferrucci, L., Simonsick, E.M., Salive, M.E. and Wallace, R.B. (1995) Lower-extremity function in persons over the age of 70 years as a predictor of subsequent disability. The New England Journal of Medicine, 332, 556-561. doi:10.1056/NEJM199503023320902

[3] Startzell, J.K., Owens, A., Mulfinger, L.M. and Cavanagh, P.R. (2000) Stair negotiation in older people: A review. Journal of the American Geriatrics Society, 48, 567-580.

[4] Guralnik, J.M., Simonsick, E.M., Ferrucci, L., Glynn, R.J., Berkman, L.F., Blazer, D.G., Scherr, P.A. and Wallace, R.B. (1994) A short physical performance battery assessing lower extremity function: Association with selfreported disability and prediction of mortality and nursing home admission. Journal of Gerontology, 49, M85-M94.

[5] Verghese, J., Wang, C., Xue, X. and Holtzer, R. (2008) Self-reported difficulty in climbing up or down stairs in nondisabled elderly. Archives of Physical Medicine and Rehabilitation, 89, 100-104. doi:10.1016/j.apmr.2007.08.129

[6] Morley, J.E. (2003) Mobility performance: A high-tech test for geriatricians. The Journals of Gerontology, Series A, 58A, 712-714. doi:10.1093/gerona/58.8.M712

[7] Ferrucci, L. (2008) The Baltimore Longitudinal Study of Aging (BLSA): A 50-year-long journey and plans for the future. The Journals of Gerontology. Series A, Biological Sciences and Medical Sciences, 63A, 1416-1419. doi:10.1093/gerona/63.12.1416

[8] Bassey, E.J., Bendall, M.J. and Pearson, M. (1998) Mus- cle strength in the triceps surae and objectively measured customary walking activity in men and women over 65 years of age. Clinical Science, 74, 85-89.

[9] Rantanen, T., Era, P. and Heikkinin, E. (1996) Maximal isometric knee extension strength and stair-mounting ability in 75- and 80-year-old men and women, Scandinavian Journal of Rehabilitation Medicine, 28, 89-93.

[10] Danneskiold-Samse, B., Kofod, V., Munter, J., Grimby, G., Schnohr, P. and Jensen, G. (1984) Muscle strength and functional capacity in 78-81-year-old men and women. European Journal of Applied Physiology and Occupational Physiology, 52, 310-314. doi:10.1007/BF01015216

[11] Plotz-Snyder, L.L., Manini, T., Plotz-Snyder, R.J. and Wolf, D.A. (2002) Functionally relevant thresholds of quadriceps femoris strength. The Journals of Gerontology. Series A, Biological Sciences and Medical Sciences, 57A, B144-B152. doi:10.1093/gerona/57.4.B144

[12] Ferrucci, L., Guralnik, J.M. and Buchner, D. (1997) Departures from linearity in the relationship between measures of muscular strength and physical performance of the lower extremities: The women's health and aging study. The Journals of Gerontology. Series A, Biological Sciences and Medical Sciences, 52A, M275-M285. doi:10.1093/gerona/52A.5.M275

[13] Bassey, E.J., Fiatarone, M.A., O’Neill, E.F., Kelly, M., Evans, W.J. and Lipsitz, L.A. (1992) Leg extensor power and functional performance in very old men and women. Clinical Science, 82, 321-327.

[14] Lauretani, F., Russo, C.R., Bandinelli, S., Bandinelli, S., Bartali, B., Cavazzini, C., Iorio, A.D., Corsi, A.M., Rantanen, T., Guralnik, J.A. and Ferrucci, L. (2003). Ageassociated changes in skeletal muscle and their effect on mobility: An operational diagnosis of sarcopenia. Journal of Applied Physiology, 95, 1851-1860.

[15] Cress, M.E. and Meyer, M. (2003) Maximal voluntary and functional performance levels needed for independence in adults aged 65 to 97 years. Physical Therapy, 83, 37-48.

[16] Buchner, D.M. and Lateur, B.J. (1991) The importance of skeletal muscle strength to physical function in older adults. Annals of Behavioral Medicine, 13, 91-98.

[17] Young, A. and Skelton, D.A. (1994) Applied physiology of strength and power in old age. International Journal of Sports Medicine, 15, 149-151. doi:10.1055/s-2007-1021037

[18] Hasegawa, R., Ialam, M.M., Lee, S.C., Koizumi, D., Rogers, M.E. and Takeshita, N. (2008) Threshold of lower body muscular strength necessary to perform ADL independently in community-dwelling older adults. Clinical Rehabilitation, 22, 902-910. doi:10.1177/0269215508094713

[19] Kennedy, D., Stratford, P.W., Pagura, S.M.C., Walsh, M. and Woodhouse, L.J. (2002) Comparison of gender and group differences in self-report and physical performance measures in total hip and knee arthroplasty candidates. The Journal of Arthroplasty, 17, 70-77. doi:10.1054/arth.2002.29324

[20] Ito, M. and Yoda, Y. (1992) Development of an apparatus 
to measure instantaneous leg extensor power output. The Japanese Journal of Physical Fitness and Sports Medicine, 11, $742-746$ (in Japanese with English abstract).

[21] Hirano, Y., Noguchi, T. and Miyashita, M. (1994) The explosive leg extensor power output and its evaluation with the function of sex and age. The Japanese Journal of Physical Fitness and Sports Medicine, 43, 113-120 (in Japanese with English abstract).

[22] Hanley, J.A. and McNeil, B.J. (1983) A method of comparing the areas under receiver operating characteristic curves derived from the same cases. Radiology, 148, 839843.

[23] Toba, K., Okochi, J. and Takahashi, T. (2005) Development of a portable fall risk index for elderly people living in the community. Japanese Journal of Geriatrics, 42, 346-352. doi:10.3143/geriatrics.42.346

[24] Kondo, K., Tanaka, T., Hirota, Y., Kawamura, H., Miura, H., Sugioka, Y., Inoue, H., Kurosawa, M. and Yamashita, T. (2006) Factors associated with functional limitation in stair climbing in female Japanese patients with knee osteoarthritis. Journal of Epidemiology/Japan Epidemiological Association, 16, 21-29.

[25] Bean, J.F., Leveille, S.G., Kiely, D.K., Bandinelli, S., Guralnik, J.M. and Ferrucci, L. (2003) A comparison of leg power and leg strength within the InCHIANTI study: Which influences mobility more? Journal of Gerontology: Medical Sciences, 58A, 728-733. doi:10.1093/gerona/58.8.M728

[26] Rantanen, T., Era, P. and Heikkinen, E. (1994) Maximal isometric strength and mobility among 75-year-old men and women. Age and Ageing, 23, 132-137. doi:10.1093/ageing/23.2.132

[27] Guralnik, J.M. and Ferrucci, L. (2003) Assessing the building blocks of function: Utilizing measures of functional limitation. American Journal of Preventive Medicine, 25, 112-121. doi:10.1016/S0749-3797(03)00174-0

[28] Suzuki, T., Bean, J.F. and Fielding, R.A. (2001) Muscle power of the ankle flexors predicts functional performance in community-dwelling older women. The Journal of the American Society for Geriatric Dentistry, 49, 11611167. doi:10.1046/j.1532-5415.2001.49232.x

[29] Morey, M.C., Pieper, C.F. and Cornoni-Huntley, J. (1998) Is there a threshold between peak oxygen uptake and selfreported physical functioning in older adults? Medicine and Science in Sports and Exercise, 30, 1223-1229. doi:10.1097/00005768-199808000-00007

[30] Posner, J.D., McCully, K.K., Landsberg, L.A., Sands, L.P., Tycenski, P., Hofmann, M.T., Wetterholt, K.L. and Shaw, C.E. (1995) Physical determinants of independence in mature women. Archives of Physical Medicine and Rehabilitation, 76, 373-380. doi:10.1016/S0003-9993(95)80664-4

[31] Brechter, J.H. and Powes, C.M. (2002) Patellofemoral joint stress during stair ascent and descent in persons with and without patellofemoral pain. Gait Posture, 16, 115123. doi:10.1016/S0966-6362(02)00090-5

[32] Papa, E. and Cappozzo, A. (2000) Sit-to-stand motor strategies investigated in able-bodied young and elderly subjects. Journal of Biomechanics, 33, 1113-1122. 